\title{
Genetic grouping for direct and maternal effects with differential assignment of groups
}

\author{
RJC Cantet ${ }^{1, *}$, RL Fernando ${ }^{2}$, D Gianola $^{3}$, I Misztal ${ }^{2}$ \\ ${ }^{1}$ Facultad de Agronomía, Universidad de Buenos Aires, \\ Departamento de Zootecnia, Av San Martín 4453 (1417), Buenos Aires, Argentina \\ ${ }^{2}$ Department of Animal Sciences, University of Illinois, Urbana, IL 61801; \\ ${ }^{3}$ University of Wisconsin, Department of Dairy Science, Madison, WI 53706-1284, USA
}

(Received 13 March 1991; accepted 26 March 1992)

Summary - Genetic grouping in additive models with maternal effects is extended to cover differential assignment of groups for direct and for maternal effects. Differential grouping provides a means for including genetic groups in animal evaluations when, for example, genetic trends for additive direct and for maternal effects are different. The extrision is based on including the same animals in both vectors of additive direct and additive maternal effects, and on exploiting the resulting Kronecker structure so as to adapt the rules of Quaas when maternal effects are absent. Computations can be performed while reading pedigree data, and no matrix manipulations are involved. An example is presented to illustrate the computations. Extension of the procedure to accommodate multiple traits is indicated.

genetic groups / direct and maternal effects / animal model / best linear unbiased prediction (BLUP)

Résumé - La constitution de groupes génétiques avec affectation différentielle selon les effets directs et maternels. La constitution de groupes génétiques dans le cadre de modèles additifs avec effet maternel est généralisée à une affectation différentielle à des groupes selon les effets directs et maternels. Ce regroupement différentiel fournit une méthode pour inclure les groupes génétiques dans l'évaluation des animaux quand, par exemple, les progrès génétiques pour les effets directs et maternels sont différents. Cette généralisation est basée sur l'inclusion des mêmes animaux dans les 2 vecteurs d'effets additifs directs et maternels et sur l'exploitation des structures de Kronecker résultantes, en adaptant les règles données par Quaas (1988) quand il n'y a pas d'effets maternels.

* Correspondence and reprints 
Les calculs peuvent être réalisés au cours de la lecture du fichier des pedigrees, et aucune manipulation matricielle n'est nécessaire. Un exemple est présenté pour illustrer les calculs. L'extension de la méthode au cas multivariable est évoquée.

groupe génétique / effet direct et maternel / modèle animal / BLUP

\section{INTRODUCTION}

Genetic grouping is a means for dealing with incomplete pedigree information in genetic evaluation (Quaas, 1988). The theory developed for additive effects (Quaas, 1988; Westel et al, 1988) was extended to accommodate maternal effects by Van Vleck (1990), but this author considered only the situation where the unknown parents are assigned to the same groups for direct and maternal effects. He also warned about possible singularities introduced by grouping when solving the mixed model equations (Henderson, 1984).

Grouping animals is often a subjective process (Quaas and Pollak, 1981; Henderson, 1984; Quaas, 1988) in which individuals are assigned to different populations (groups) based on some attribute such as year of birth. Genetic grouping is somewhat less arbitrary in the sense that only unknown parent animals are assigned to groups (Quaas, 1988). When there are maternal effects, every unknown parent must be assigned to a group for direct effects and to a group for maternal effects, and there may be situations in which the criteria for constructing groups for the direct effects differ from those used for the maternal effects. An example is when genetic trends for direct and for maternal effects are different. The objective of this study is to extend the theory of genetic grouping in models with maternal effects so as to allow for differential criteria to be used when assigning groups for directs effects and groups for maternal effects.

\section{THEORY}

Let $y_{i j}$ be a record made by individual $i$ with dam $j$. After Willham (1963) and Quaas and Pollak (1980), an additive model for the maternally influenced record $y_{i j}$ is:

$$
y_{i j}=\mathbf{x}_{i}^{\prime} \boldsymbol{\beta}+a_{o i}+a_{m j}+e_{m j}+e_{o i}
$$

where $\mathbf{x}_{i}^{\prime}$ is a row of the incidence matrix relating the record of individual $i$ to an unknown vector $\boldsymbol{\beta}$ of fixed effects, $a_{o i}$ is the direct breeding value (BV) of $i$ for direct effects, $a_{m j}$ is the BV of dam $j$ for maternal effects, $e_{m j}$ is an environmental contribution common to all progeny raised by $j$ and $e_{o i}$ is an environmental deviation peculiar to the record made by individual $i$. The model is such that $a_{o i}, a_{m j}, e_{o i}$ are random variables with $\operatorname{Var}\left(a_{o i}\right)=\sigma_{A o}^{2}, \operatorname{Var}\left(a_{m j}\right)=$ $\sigma_{A m}^{2}, \operatorname{cov}\left(a_{o i}, a_{m j}\right)=r_{i j} \sigma_{A o A m}, \operatorname{Var}\left(e_{m j}\right)=\sigma_{E m}^{2}$ and $\operatorname{Var}\left(e_{o i}\right)=\sigma_{E o}^{2} ; r_{i j}$ is the additive relationship between $i$ and $j, a_{i j}$ being equal to $1 / 2$ in this case. All random variables are assumed to be mutually independent, with the exception of $a_{o i}$ and $a_{m j}$. The $E\left(y_{i j}\right)$ is described in Mixed model equations. 
The BV's for direct and maternal effects of any individual can be described as the average of the BV's of its parents plus an independently distributed Mendelian sampling residual $\phi$ (Bulmer, 1985). Letting $k$ be the sire of $i$, the direct BV of $i$ is:

$$
a_{o i}=\frac{1}{2} a_{o k}+\frac{1}{2} a_{o j}+\phi_{o i}
$$

In the same way, the maternal BV of $i$ is:

$$
a_{m i}=\frac{1}{2} a_{m k}+\frac{1}{2} a_{m j}+\phi_{m i}
$$

Following Quaas (1988), in the absence of inbreeding $\operatorname{Var}\left(\phi_{o i}\right)=1 / 2 \sigma_{A o}^{2}$, and $\operatorname{Var}\left(\phi_{m i}\right)=1 / 2 \sigma_{A m}^{2}$. Also:

$$
\begin{gathered}
\operatorname{cov}\left(a_{o i}, a_{m i}\right)=\frac{1}{4}\left[\operatorname{cov} a_{o k}, a_{m k}\right)+\operatorname{cov}\left(a_{o k}, a_{m j}\right) \\
\left.+\operatorname{cov}\left(a_{o j}, a_{m k}\right)+\operatorname{cov}\left(a_{o j}, a_{m j}\right)\right]+\operatorname{cov}\left(\phi_{o i}, \phi_{m i}\right) \\
=\frac{1}{2} \sigma_{A o A m}+\operatorname{cov}\left(\phi_{o i}, \phi_{m i}\right)=\sigma_{A o A m}
\end{gathered}
$$

because $k$ and $j$ are unrelated. From the preceding, $\operatorname{cov}\left(\phi_{o i}, \phi_{m i}\right)=1 / 2 \sigma_{A o A m}$. Let the positive-definite matrix $\mathbf{G}_{0}$ be:

$$
\mathbf{G}_{0}=\left[\begin{array}{cc}
\sigma_{A o}^{2} & \sigma_{A o A m} \\
\sigma_{A o A m} & \sigma_{A m}^{2}
\end{array}\right]
$$

Thus:

$$
\operatorname{Var}\left[\begin{array}{c}
\phi_{o i} \\
\phi_{m i}
\end{array}\right]=\frac{1}{2} \mathbf{G}_{0}
$$

The animal model with groups and relationships (Robinson, 1986; Quaas, 1988; Westell et al 1988; is based on arranging BV's of all animals into 2 different vectors, $\mathbf{a}$ and $\mathbf{a}_{b}$. Every identified individual in the pedigree has a direct $\mathrm{BV}$ in the $a \times 1$ vector $\mathbf{a}_{o}$ and a maternal $\mathrm{BV}$ in the $a \times 1$ vector $\mathbf{a}_{m}$ such that $\mathbf{a}^{\prime}=\left[\mathbf{a}_{o}^{\prime}, \mathbf{a}_{m}^{\prime}\right]$. Unknown animals (parents) from which individuals in a are derived have their BV's represented in the $2 b \times 1$ vector $\mathbf{a}_{b}^{\prime}=\left[\mathbf{a}_{b o}^{\prime}, \mathbf{a}_{b m}^{\prime}\right]$. These are the "base" population animals, and they are assumed each to have a single progeny represented in a. Let $\mathbf{P}_{b}$ (of order $a \times b$ ) and $\mathbf{P}$ (of order $a \times a$ ) be matrices relating $\mathrm{BV}$ of progeny to $\mathrm{BV}$ of unknown and identified individuals, respectively. If base animals were known, a matrix version of [2] and [3] would be given by $\mathbf{a}=\left(\mathbf{I}_{2} \otimes \mathbf{P}\right) \mathbf{a}+\boldsymbol{\phi}$, where $\boldsymbol{\phi}$ is a vector that results from stacking the Mendelian residuals for direct and maternal effects. As in Quaas (1988), it will be assumed that Mendelian residuals have expectation $\mathrm{E}(\boldsymbol{\phi})=\mathbf{0}$ and, because no inbreeding is assumed, $\operatorname{Var}(\phi)=1 / 2 \mathbf{G}_{o} \otimes \mathbf{I}_{a}$. This variance-covariance matrix follows from expression [4]. If there is inbreeding, the matrix $\mathbf{I}_{a}$ must be replaced by a diagonal 
matrix with elements $d_{i i}=1 / 2-\left(F_{S i}+F_{D i}\right) / 4$, where $F_{S i}$ and $F_{D i}$ are the inbreeding coefficients of the sire and the dam of individual $i$.

The vector $\mathbf{a}$ is better represented conceptually (Quaas, 1988) by the expression:

$$
\mathbf{a}=\left[\mathbf{I}_{2} \otimes \mathbf{P}_{b}\right] \mathbf{a}_{b}+\left[\mathbf{I}_{2} \otimes \mathbf{P}\right] \mathbf{a}+\boldsymbol{\phi}
$$

Rearranging:

and solving for a:

$$
\mathbf{a}-\left[\mathbf{I}_{2} \otimes \mathbf{P}\right] \mathbf{a}=\left[\mathbf{I}_{2} \otimes \mathbf{P}_{b}\right] \mathbf{a}_{b}+\boldsymbol{\phi}
$$

$$
\mathbf{a}=\left[\mathbf{I}_{2} \otimes\left(\mathbf{I}_{a}-\mathbf{P}\right)\right]^{-1}\left[\left(\mathbf{I}_{2} \otimes \mathbf{P}_{b}\right) \mathbf{a}_{b}+\boldsymbol{\phi}\right]
$$

The base animals are assumed to be drawn at random from the distribution

$$
\mathbf{a}_{b} \sim\left(\mathbf{Q}_{b} \mathbf{g}, \mathbf{G}_{0} \otimes \mathbf{I}_{b}\right)
$$

where $\mathbf{Q}_{b}$ relates base animals to the "base" population means, $\mathbf{g}$. Hence, base animals are unrelated but do not necessarily have the same mean. More explicitly:

$$
\mathrm{E}\left(\mathbf{a}_{b}\right)=\mathrm{E}\left[\begin{array}{c}
\mathbf{a}_{b o} \\
\mathbf{a}_{b m}
\end{array}\right]=\left[\begin{array}{cc}
\mathbf{Q}_{b o} & \mathbf{0} \\
\mathbf{0} & \mathbf{Q}_{b m}
\end{array}\right]\left[\begin{array}{c}
\mathbf{g}_{o} \\
\mathbf{g}_{m}
\end{array}\right]
$$

where $\mathbf{g}_{o}$ and $\mathbf{g}_{m}$ are the "base" mean vectors for direct and maternal effects, respectively, and the matrices $\mathbf{Q}_{b o}$ and $\mathbf{Q}_{b m}$ relate base animals to their respective population means. In general, $\mathbf{Q}_{b o}$ and $\mathbf{Q}_{b m}$ may be different, even though including the same animals in $\mathbf{a}_{o}$ and in $\mathbf{a}_{m}$ forces $\mathbf{a}_{b o}$ and $\mathbf{a}_{b m}$ to correspond to the same base animals.

To exemplify, consider the following pedigree:

$\begin{array}{ccc}\text { Individual } & \text { Sire } & \text { Dam } \\ \mathrm{A} & \mathrm{a}\left(\mathrm{D}_{2}, \mathrm{M}_{1}\right) & \mathrm{b}\left(\mathrm{D}_{1}, \mathrm{M}_{1}\right) \\ \mathrm{B} & \mathrm{c}\left(\mathrm{D}_{1}, \mathrm{M}_{1}\right) & \mathrm{d}\left(\mathrm{D}_{1}, \mathrm{M}_{2}\right) \\ \mathrm{C} & \mathrm{A} & \mathrm{B} \\ \mathrm{D} & \mathrm{e}\left(\mathrm{D}_{2}, \mathrm{M}_{2}\right) & \mathrm{B}\end{array}$

Capital letters denote identified individuals and lower case letters the unknown or "phantom" parents. Symbols in parentheses indicate group (direct, maternal) of the unknown parents. There are 2 groups for direct effects $\left(D_{1}\right.$ and $\left.D_{2}\right)$ and 2 groups for maternal effects $\left(M_{1}\right.$ and $\left.M_{2}\right)$; note that some unknown parents $(a, d)$ have been assigned to different groups for direct and maternal effects. The matrix $\left[\mathbf{P}_{b} \mid \mathbf{P}\right]$ is:

$$
\left[\mathbf{P}_{b} \mid \mathbf{P}\right]=\left[\begin{array}{ccccc:cccc}
0.5 & 0.5 & 0.0 & 0.0 & 0.0 & 0.0 & 0.0 & 0.0 & 0.0 \\
0.0 & 0.0 & 0.5 & 0.5 & 0.0 & 0.0 & 0.0 & 0.0 & 0.0 \\
0.0 & 0.0 & 0.0 & 0.0 & 0.0 & 0.5 & 0.5 & 0.0 & 0.0 \\
0.0 & 0.0 & 0.0 & 0.0 & 0.5 & 0.0 & 0.5 & 0.0 & 0.0
\end{array}\right]
$$


The matrix $\mathbf{Q}_{b}$ is:

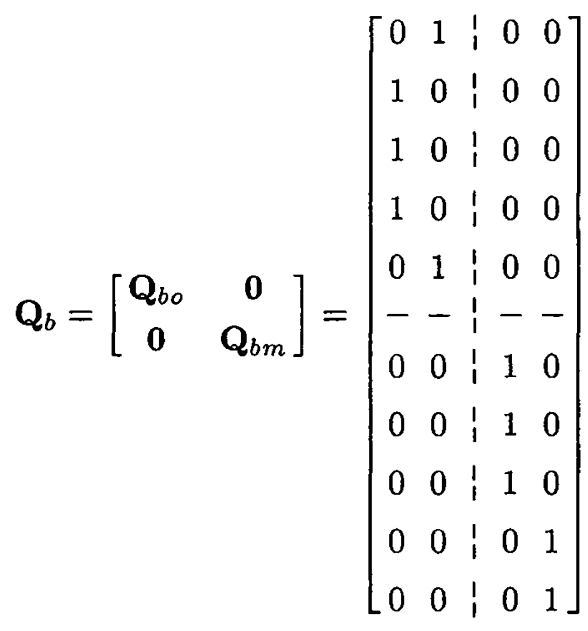

This formulation allows the rules of Quaas to be extended (1988) for writing the mixed model equations for an animal model with genetic groups for direct and maternal effects in a simple way.

\section{Expectation of a}

Using [5], we have:

$$
\begin{aligned}
\mathrm{E}(\mathbf{a})= & {\left[\mathbf{I}_{2} \otimes\left(\mathbf{I}_{a}-\mathbf{P}\right)\right]^{-\mathbf{1}}\left[\left(\mathbf{I}_{2} \otimes \mathbf{P}_{b}\right) \mathrm{E}\left(\mathbf{a}_{b}\right)+\mathrm{E}(\boldsymbol{\phi})\right] } \\
& =\left[\mathbf{I}_{2} \otimes\left(\mathbf{I}_{a}-\mathbf{P}\right)^{-\mathbf{1}} \mathbf{P}_{b}\right] \mathbf{Q}_{b} \mathbf{g}=\mathbf{Q g}
\end{aligned}
$$

for $\mathbf{Q}=\left[\mathbf{I}_{2} \otimes\left(\mathbf{I}_{a}-\mathbf{P}\right)^{-1} \mathbf{P}_{b}\right] \mathbf{Q}_{b}$. The rectangular matrix $\mathbf{Q}$ is made of 2 blocks: $\left(\mathbf{I}_{a}-\mathbf{P}^{-1} \mathbf{P}_{b} \mathbf{Q}_{b o}\right.$ and $\left(\mathbf{I}_{a}-\mathbf{P}\right)^{-1} \mathbf{P}_{b} \mathbf{Q}_{b m}$. The first block is the same as in Quaas (1988) for a model without maternal effects.

\section{Variance of a}

From [5]:

$$
\begin{gathered}
\operatorname{Var}(\mathbf{a})=\left[\mathbf{I}_{2} \otimes\left(\mathbf{I}_{a}-\mathbf{P}\right)\right]^{-1}\left[\left[\mathbf{I}_{2} \otimes \mathbf{P}_{b}\right] \operatorname{Var}\left(\mathbf{a}_{b}\right)\left[\mathbf{I}_{2} \otimes \mathbf{P}_{b}^{\prime}\right]+\operatorname{Var}(\boldsymbol{\phi})\right]\left[\mathbf{I}_{2} \otimes\left(\mathbf{I}_{a}-\mathbf{P}^{\prime}\right)\right]^{-1} \\
=\left[\mathbf{I}_{2} \otimes\left(\mathbf{I}_{a}-\mathbf{P}\right)\right]^{-1}\left[\left(\mathbf{I}_{2} \otimes \mathbf{P}_{b}\right)\left(\mathbf{G}_{0} \otimes \mathbf{I}_{b}\right)\left(\mathbf{I}_{2} \otimes \mathbf{P}_{b}^{\prime}\right)+\frac{1}{2} \mathbf{G}_{0} \otimes \mathbf{I}_{a}\right]\left[\mathbf{I}_{2} \otimes\left(\mathbf{I}_{a}-\mathbf{P}^{\prime}\right)\right]^{-1} \\
=\left[\mathbf{I}_{2} \otimes\left(\mathbf{I}_{a}-\mathbf{P}\right)\right]^{-1}\left[\mathbf{G}_{0} \otimes\left(\mathbf{P}_{b} \mathbf{P}_{b}^{\prime}+\frac{1}{2} \mathbf{I}_{a}\right)\right]\left[\mathbf{I}_{2} \otimes\left(\mathbf{I}_{a}-\mathbf{P}^{\prime}\right)\right]^{-1} \\
=\mathbf{G}_{0} \otimes\left(\mathbf{I}_{a}-\mathbf{P}\right)^{-1}\left(\mathbf{P}_{b} \mathbf{P}_{b}^{\prime}+\frac{1}{2} \mathbf{I}_{b}\right)\left(\mathbf{I}_{a}-\mathbf{P}^{\prime}\right)^{-1}=\mathbf{G}
\end{gathered}
$$


Since $\operatorname{Var}(\mathbf{a})=\mathbf{G}_{0} \otimes \mathbf{A}$, it follows that:

$$
\mathbf{A}=\left(\mathbf{I}_{a}-\mathbf{P}\right)^{-1}\left(\mathbf{P}_{b} \mathbf{P}_{b}^{\prime}+\frac{1}{2} \mathbf{I}_{a}\right)\left(\mathbf{I}_{a}-\mathbf{P}^{\prime}\right)^{-1}
$$

Quaas (1988) pointed out that $\mathbf{P}_{b} \mathbf{P}_{b}^{\prime}=\operatorname{Diag}\left\{0.25 m_{i}\right\}$, for $m_{i}=0,1,2=$ the number of base parents of the $i$ th individual. Hence:

$$
\mathbf{A}=\left(\mathbf{I}_{a}-\mathbf{P}\right)^{-1} \mathbf{D}\left(\mathbf{I}_{a}-\mathbf{P}^{\prime}\right)^{-1}
$$

where $\mathbf{D}=\operatorname{Diag}\left\{0.25 m_{i}+0.5\right\}$. Hence:

$$
\mathbf{A}^{-1}=\left(\mathbf{I}_{a}-\mathbf{P}^{\prime}\right) \mathbf{D}^{-1}\left(\mathbf{I}_{a}-\mathbf{P}\right)
$$

and

$$
\begin{aligned}
\mathbf{G}^{-1} & =\mathbf{G}_{0}^{-1} \otimes \mathbf{A}^{-1}=\mathbf{G}_{0}^{-1} \otimes\left(\mathbf{I}_{a}-\mathbf{P}^{\prime}\right) \mathbf{D}^{-1}\left(\mathbf{I}_{a}-\mathbf{P}\right) \\
& =\left[\mathbf{I}_{2} \otimes\left(\mathbf{I}_{a}-\mathbf{P}^{\prime}\right)\right]\left(\mathbf{G}_{0}^{-1} \otimes \mathbf{D}^{-1}\right)\left[\mathbf{I}_{2} \otimes\left(\mathbf{I}_{a}-\mathbf{P}\right)\right]
\end{aligned}
$$

\section{Mixed model equations}

A matrix version of model [1] is:

$$
\mathbf{y}=\mathbf{X} \boldsymbol{\beta}+\mathbf{Z}_{o} \mathbf{a}_{o}+\mathbf{Z}_{m} \mathbf{a}_{m}+\mathbf{E}_{m} \mathbf{e}_{m}+\mathbf{e}_{o}
$$

where $\mathbf{y}, \boldsymbol{\beta}, \mathbf{a}_{o}, \mathbf{a}_{m}, \mathbf{e}_{m}$ and $\mathbf{e}_{o}$ are the vectors of records, and of unknown fixed, direct and maternal BV's, maternal environmental and direct environmental effects, respectively. In the same way, the incidence matrices $\mathbf{X}, \mathbf{Z}_{o}, \mathbf{Z}_{m}$ and $\mathbf{E}_{m}$ relate records to fixed effects, direct and maternal $\mathrm{BV}$ and maternal environmental effects. Correct specification of the coefficients for $\sigma_{A o A m}$ and $\sigma_{A m}^{2}$ in the variancecovariance matrix of $\mathbf{y}$ in [11], for any pair of individuals with records, requires the additive relationships between each individual and the dam of the other and the additive relationship between the dams (William, 1963). If an animal with a record in $\mathbf{y}$ has an unidentified ("phantom") dam, mis-specification of $\operatorname{Var}(\mathbf{y})$ results due to taking those additive relationships as if there were zero. One solution is to include the BV for direct and maternal effects of the "phantom" dam of the individual in $\mathbf{a}_{o}$ and $\mathbf{a}_{m}$, respectively. Note that this has the effect of increasing the size of the system of equations by twice the number of unknown dams of individuals with records in y. Maternal environmental effects of "phantom" dams may also be included in $\mathbf{e}_{m}$ to force $\sigma_{E m}^{2}$ to be present in the variance of animals with a record in $\mathbf{y}$ and with an unknown dam, as discussed by Henderson (1988). This procedure also increases the number of equations to be solved. A more efficient strategy is to lump the maternal environmental effects of "phantom" dams with the residual of their progeny keeping the residual variance diagonal. Letting $\mathbf{Z}=\left[\mathbf{Z}_{o}^{\prime} \mathbf{Z}_{m}\right]$, it is assumed that:

$$
\mathrm{E}\left[\begin{array}{c}
\mathbf{a} \\
\mathbf{e}_{m} \\
\mathbf{e}_{o}
\end{array}\right]=\left[\begin{array}{c}
\mathbf{Q g} \\
\mathbf{0} \\
\mathbf{0}
\end{array}\right] \quad \operatorname{Var}\left[\begin{array}{c}
\mathbf{a} \\
\mathbf{e}_{m} \\
\mathbf{e}_{o}
\end{array}\right]=\left[\begin{array}{ccc}
\mathbf{G}_{0} \otimes \mathbf{A} & \mathbf{0} & \mathbf{0} \\
\mathbf{0} & \mathbf{I}_{d} \sigma_{E m}^{2} & \mathbf{0} \\
\mathbf{0} & \mathbf{0} & \mathbf{I}_{n} \sigma_{E_{o}}^{2}
\end{array}\right]
$$


Therefore, $\mathrm{E}(\mathbf{y})=\mathbf{X} \boldsymbol{\beta}+\mathbf{Z Q g}$ and $\operatorname{Var}(\mathbf{y})=\mathbf{Z}\left(\mathbf{G}_{0} \otimes \mathbf{A}\right) \mathbf{Z}^{\prime}+\mathbf{E}_{m} \mathbf{E}_{m}^{\prime} \sigma_{E m}^{2}+\mathbf{I}_{n} \sigma_{E o}^{2}$.

Using the QP "transformation" (Quaas and Pollak, 1981), modified mixed model equations for [11] are:

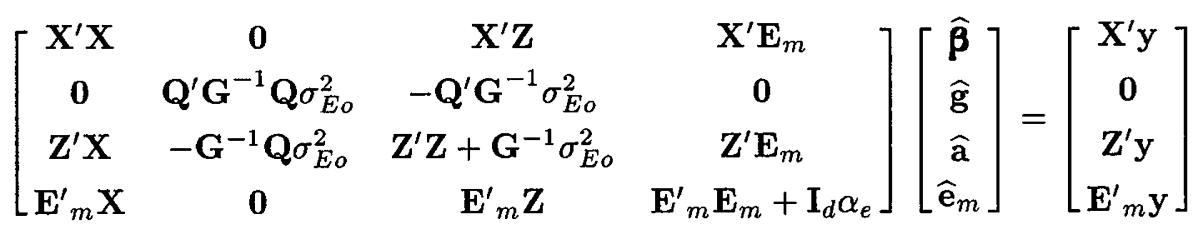

where $\alpha_{e}=\sigma_{E o}^{2} / \sigma_{E m}^{2}$. On defining $\mathbf{W}=\left[\mathbf{X}: \mathbf{0}: \mathbf{Z}: \mathbf{E}_{m}\right], \widehat{\boldsymbol{\theta}}^{\prime}=\left[\widehat{\boldsymbol{\beta}}^{\prime}: \widehat{\mathbf{g}}^{\prime}: \widehat{\mathbf{a}}^{\prime}::_{m}^{\prime}\right]$ and:

$$
\mathbf{A}^{*}=\left[\begin{array}{cccc}
\mathbf{0} & \mathbf{0} & \mathbf{0} & \mathbf{0} \\
\mathbf{0} & \mathbf{Q}^{\prime} \mathbf{G}^{-1} \mathbf{Q} & -\mathbf{Q}^{\prime} \mathbf{G}^{-1} & \mathbf{0} \\
\mathbf{0} & -\mathbf{G}^{-1} \mathbf{Q} & \mathbf{G}^{-1} & \mathbf{0} \\
\mathbf{0} & \mathbf{0} & \mathbf{0} & \mathbf{I}_{d}\left(\sigma_{E m}^{2}\right)^{-1}
\end{array}\right] \sigma_{E o}^{2}
$$

the above equations can be expressed as $\left[\mathbf{W}^{\prime} \mathbf{W}+\mathbf{A}^{*}\right] \widehat{\boldsymbol{\theta}}=\mathbf{W}^{\prime} \mathbf{y}$.

\section{Rules for calculating $A^{*}$}

For the method to be computationally feasible $\mathbf{A}^{*}$ must be calculated without performing matrix multiplications. The last block in $\mathbf{A}^{*}$ is diagonal and meets this requirement. The central block is the "genetic" part of $\mathbf{A}^{*}$ and can be calculated by simple rules which are an extension of the work of Quaas (1988). A referee pointed out a simple way of deriving these rules and his proof is adapted here. Observe that the central block in $\mathbf{A}^{*}$ (without $\sigma_{E o}^{2}$ ) is:

$$
\left[\begin{array}{cc}
\mathbf{Q}^{\prime} \mathbf{G}^{-1} \mathbf{Q} & -\mathbf{Q}^{\prime} \mathbf{G}^{-1} \\
-\mathbf{G}^{-1} \mathbf{Q} & \mathbf{G}^{-1}
\end{array}\right]=\left[\begin{array}{c}
\mathbf{Q}^{\prime} \\
-\mathbf{I}_{2 a}
\end{array}\right] \mathbf{G}^{-1}\left[\mathbf{Q}-\mathbf{I}_{2} a\right]
$$

and, on using $\mathbf{Q}=\left[\mathbf{I}_{2} \otimes\left(\mathbf{I}_{a}-\mathbf{P}\right)^{-1} \mathbf{P}_{b}\right] \mathbf{Q}_{b}$ and $\mathbf{G}^{-1}$ as in [10], the above expression is equal to:

$$
\begin{gathered}
{\left[\begin{array}{c}
-\mathbf{Q}^{\prime} \\
\mathbf{I}_{2 a}
\end{array}\right]\left[\mathbf{I}_{2} \otimes\left(\mathbf{I}_{a}-\mathbf{P}^{\prime}\right)\right]\left(\mathbf{G}_{0}^{-1} \otimes \mathbf{D}^{-1}\right)\left[\mathbf{I}_{2} \otimes\left(\mathbf{I}_{a}-\mathbf{P}\right)\right]\left[-\mathbf{Q} \mathbf{I}_{2 a}\right]} \\
=\left[\begin{array}{c}
-\mathbf{Q}^{\prime}\left[\mathbf{I}_{2} \otimes\left(\mathbf{I}_{a}-\mathbf{P}^{\prime}\right)\right] \\
{\left[\mathbf{I}_{2} \otimes\left(\mathbf{I}_{a}-\mathbf{P}^{\prime}\right)\right]}
\end{array}\right]\left(\mathbf{G}_{0}^{-1} \otimes \mathbf{D}^{-1}\right)\left[-\left[\mathbf{I}_{2} \otimes\left(\mathbf{I}_{a}-\mathbf{P}\right)\right] \mathbf{Q}\left[\mathbf{I}_{2} \otimes\left(\mathbf{I}_{a}-\mathbf{P}\right)\right]\right] \\
=\mathbf{H}^{\prime}\left(\mathbf{G}_{0}^{-1} \otimes \mathbf{D}^{-1}\right) \mathbf{H}
\end{gathered}
$$

Note that $\mathbf{H}$ can be written as:

$$
\mathbf{H}=\left[-\left[\mathbf{I}_{2} \otimes\left(\mathbf{I}_{a}-\mathbf{P}\right)\right] \mathbf{Q} \quad\left[\mathbf{I}_{2} \otimes\left(\mathbf{I}_{a}-\mathbf{P}\right)\right]\right]
$$




$$
\begin{aligned}
& =\left[-\left[\mathbf{I}_{2} \otimes\left(\mathbf{I}_{a}-\mathbf{P}\right)\right]\left[\mathbf{I}_{2} \otimes\left(\mathbf{I}_{a}-\mathbf{P}\right)^{-1} \mathbf{P}_{b}\right] \mathbf{Q}_{b} \quad\left[\mathbf{I}_{2} \otimes\left(\mathbf{I}_{a}-\mathbf{P}\right)\right]\right] \\
& =\left[-\left[\begin{array}{ll}
\mathbf{I}_{2} \otimes \mathbf{P}_{b} \\
\mathbf{Q}_{b} & {\left[\mathbf{I}_{2} \otimes\left(\mathbf{I}_{a}-\mathbf{P}\right]\right.}
\end{array}\right]\right. \\
& =\left[\begin{array}{cccc}
\mathbf{P}_{b} \mathbf{Q}_{b o} & \mathbf{0} & \left(\mathbf{I}_{a}-\mathbf{P}\right) & \mathbf{0} \\
\mathbf{0} & -\mathbf{P}_{b} \mathbf{Q}_{b m} & \mathbf{0} & \left(\mathbf{I}_{a}-\mathbf{P}\right)
\end{array}\right]=\left[\begin{array}{l}
\mathbf{H}_{1} \\
\mathbf{H}_{2}
\end{array}\right]
\end{aligned}
$$

In absence of maternal effects, [13] reduces to the expression obtained by Quaas (1988; page 1343) for direct effects only. Let $g^{i j}$ be element $i, j$ of $\mathbf{G}_{0}^{-1}$. Then, using [13] on [12], we have that the "genetic" part of $\mathbf{A}^{*}$ is equal to:

$$
\begin{gathered}
=\sum_{i=1}^{2} \sum_{j=1}^{2} g^{i j} \mathbf{H}_{i}^{\prime} \mathbf{D}^{-1} \mathbf{H}_{j} \\
{\left[\begin{array}{cc}
g^{11} \mathbf{H}_{1}^{\prime} \mathbf{D}^{-1} \mathbf{H}_{1} & g^{12} \mathbf{H}_{1} \mathbf{D}^{-1} \mathbf{H}_{2} \\
g^{21} \mathbf{H}_{2}^{\prime} \mathbf{D}^{-1} \mathbf{H}_{1} & g^{22} \mathbf{H}_{2}^{\prime} \mathbf{D}^{-1} \mathbf{H}_{2}
\end{array}\right]} \\
=\sum_{i=1}^{2} \sum_{j=1}^{2} g^{i j}\left[\sum_{k=1}^{a} d_{k}^{-1} \mathbf{h}_{i: k} \mathbf{h}_{j: k}^{\prime}\right] \\
=\sum_{k=1}^{a}\left[\sum_{i=1}^{2} \sum_{j=1}^{2} g^{i j} d_{k}^{-1} \mathbf{h}_{i: k} \mathbf{h}_{j: k}^{\prime}\right]
\end{gathered}
$$

where $d_{k}^{-1}$ is diagonal element $k$ of matrix $\mathbf{D}^{-1}$ and $\mathbf{h}_{i: k}^{\prime}$ (see 14) is the $k t h$ row of $\mathbf{H}_{i}$. Most elements in each of these rows are zeroes except for 2 negative halves (corresponding to a sire or a sire base group and to a dam or a base dam group) and a one (corresponding to the individual). The first $a$ rows correspond to direct effects and the rest to maternal effects.

Expression [14] shows that the 3 non-zero elements in each row of $\mathbf{H}$ make each known individual to "contribute" 36 times $\left(=3^{2} \times 2 \times 2\right)$ to the "genetic" part of $\mathbf{A}^{*}$. The contributions can be described letting $i, f, j, k, l$ and $m$ represent the row or column or $\mathbf{A}^{*}$ associated with:

$i=$ direct effect of an individual;

$f=$ maternal genetic effect of the same individual;

$j=$ direct effect of the sire of the individual if the sire is known, or group for direct effects of the unknown sire;

$k=$ direct effect of the dam of the individual if the dam is known, or group for direct effects of the unknown dam;

$l=$ genetic maternal effect of the sire of the individual if the sire is known, or group for maternal effects of the unknown sire;

$m=$ genetic maternal effect of the dam of the individual if the dam is known, or group for maternal effects of the unknown dam. 
Therefore, the 36 contributions result from all pairwise combinations of the above subscripts. As in Quaas (1988), let , $=0,1$ or 2 be the number of unknown parents of $i$ and $x=4 /(n+2)$ and put:

$$
\mathbf{G}_{0}^{-1} \sigma_{E o}^{2}=\left[\begin{array}{ll}
\alpha & \lambda \\
\lambda & \beta
\end{array}\right]
$$

Then, each known individual makes the following contributions which are added to the "genetic" part of $\mathbf{A}^{*}$ :

\begin{tabular}{cccc} 
Add & \multicolumn{3}{c}{ To element } \\
$x \alpha$ & \multicolumn{3}{c}{$(i, i)$} \\
$x \lambda$ & \multicolumn{3}{c}{$(i, f) ;(f, i)$} \\
$x \beta$ & \multicolumn{3}{c}{$(f, f)$} \\
$-0.5 x \alpha$ & $(i, j) ; \quad(i, k) ; \quad(j, i) ;$ & $(k, i)$ \\
$-0.5 x \lambda$ & $(f, j) ; \quad(f, k) ; \quad(j, f) ;$ & $(k, f)$ \\
& $(i, l) ; \quad(i, m) ; \quad(l, i) ;$ & $(m, i)$ \\
$-0.5 x \beta$ & $(f, l) ; \quad(f, m) ; \quad(l, f) ;$ & $(m, f)$ \\
$0.25 x \alpha$ & $(j, j) ; \quad(j, k) ; \quad(k, j) ;$ & $(k, k)$ \\
$0.25 x \lambda$ & $(j, l) ; \quad(j, m) ; \quad(k, l) ;$ & $(k, m)$ \\
& $(l, j) ; \quad(m, j) ; \quad(l, k) ;$ & $(m, k)$ \\
$0.25 x \beta$ & $(l, l) ; \quad(l, m) ; \quad(m, l) ;$ & $(m, m)$
\end{tabular}

Using these rules plus [15], the contributions of each animal to elements of the "genetic" part of $\mathbf{A}^{*}$, for the example, are displayed in table I.

Using these contributions the "genetic" part of $\mathbf{A}^{*}$ is:

$$
g_{m} g_{o}\left[\begin{array}{cc|cc|cccc|cccc}
1.25 \alpha & 0.25 \alpha & \lambda & 0.5 \lambda & -0.5 \alpha & -\alpha & 0 & 0 & -0.5 \lambda & -\lambda & 0 & 0 \\
0.25 \alpha & 0.58 \alpha & 0.5 \lambda & 0.33 \lambda & -0.5 \alpha & 0.33 \alpha & 0 & -0.66 \alpha & -0.5 \lambda & 0.33 \lambda & 0 & 0.66 \lambda \\
\hdashline \lambda & 0.5 \lambda & 1.25 \beta & 0.25 \beta & -\lambda & -0.5 \lambda & 0 & 0 & -\beta & -0.5 \beta & 0 & 0 \\
\hdashline & a_{m} & 0.5 \lambda & -0.5 & a_{m} \\
0.5 \lambda & 0.33 \lambda & 0.25 \beta & 0.58 \beta & 0 & -0.17 \lambda & 0 & -0.66 \lambda & 0 & -0.17 \beta & 0 & -0.66 \beta \\
\hdashline-0.5 \alpha & -0.5 \alpha & -\lambda & 0 & 1.5 \alpha & 0.5 \alpha & -\alpha & 0 & 1.5 \lambda & 0.5 \lambda & -\lambda & 0 \\
-\alpha & 0.33 \alpha & -0.5 \lambda & -0.17 \lambda & 0.5 \alpha & 1.83 \alpha & -\alpha & -0.66 \alpha & 0.5 \lambda & 1.83 \lambda & -\lambda & -0.66 \lambda \\
0 & 0 & 0 & 0 & -\alpha & -\alpha & 2 \alpha & 0 & -\lambda & -\lambda & 2 \lambda & 0 \\
0 & -0.66 \alpha & 0 & -0.66 \lambda & 0 & 0.66 \alpha & 0 & 1.33 \alpha & 0 & -0.66 \lambda & 0 & 1.33 \lambda \\
\hdashline-0.5 \lambda & -0.5 \lambda & -\beta & 0 & 1.5 \lambda & 0.5 \lambda & -\lambda & 0 & 1.5 \beta & 0.5 \beta & -\beta & 0 \\
-\lambda & 0.33 \lambda & -0.5 \beta & -0.17 \beta & 0.5 \lambda & 1.83 \lambda & -\lambda & -0.66 \lambda & 0.5 \beta & 1.83 \beta & -\beta & -0.66 \beta \\
0 & 0 & 0 & 0 & -\lambda & -\lambda & 2 \lambda & 0 & -\beta & -\beta & 2 \beta & 0 \\
0 & -0.66 \lambda & 0 & -0.66 \beta & 0 & -0.66 \lambda & 0 & 1.33 \lambda & 0 & -0.66 \beta & 0 & 1.33 \beta
\end{array}\right]
$$


Table I. Contributions to elements of the "genetic" part of $\mathbf{A}^{*}$ in the example.

\section{Animal}

\begin{tabular}{|c|c|c|c|}
\hline$A$ & $B$ & $C$ & $D$ \\
\hline to $\left(A_{D}, A_{D}\right)$ & to $\left(\mathrm{B}_{\mathrm{D}}, \mathrm{B}_{\mathrm{D}}\right)$ & $2 \alpha$ to $\left(\mathrm{C}_{\mathrm{D}}, \mathrm{C}_{\mathrm{D}}\right)$ & $1.33 \alpha$ to $\left(\mathrm{D}_{\mathrm{D}}, \mathrm{D}_{\mathrm{D}}\right)$ \\
\hline to $\left(A_{D}, A_{M}\right)$ & to $\left(\mathrm{B}_{\mathrm{D}}, \mathrm{B}_{\mathrm{M}}\right)$ & $2 \lambda$ to $\left(\mathrm{C}_{\mathrm{D}}, \mathrm{C}_{\mathrm{M}}\right)$ & $1.33 \lambda$ to $\left(\mathrm{D}_{\mathrm{D}}, \mathrm{D}_{\mathrm{M}}\right)$ \\
\hline to $\left(A_{M}, A_{D}\right)$ & to $\left(\mathrm{B}_{\mathrm{M}}, \mathrm{B}_{\mathrm{D}}\right)$ & $2 \lambda$ to $\left(C_{M}, C_{D}\right)$ & $1.33 \lambda$ to $\left(\mathrm{D}_{\mathrm{M}}, \mathrm{D}_{\mathrm{D}}\right)$ \\
\hline$\beta$ to $\left(A_{M}, A_{M}\right)$ & $\beta$ to $\left(B_{M}, B_{M}\right)$ & $2 \beta$ to $\left(\mathrm{C}_{\mathrm{M}}, \mathrm{C}_{\mathrm{M}}\right)$ & $1.33 \beta$ to $\left(\mathrm{D}_{\mathrm{M}}, \mathrm{D}_{\mathrm{M}}\right)$ \\
\hline$-0.5 \alpha$ to $\left(\mathrm{A}_{\mathrm{D}}, \mathrm{D}_{2}\right)$ & $-0.5 \alpha$ to $\left(\mathrm{B}_{\mathrm{D}}, \mathrm{D}_{1}\right)$ & $-\alpha$ to $\left(C_{D}, A_{D}\right)$ & $-0.66 \alpha$ to $\left(\mathrm{D}_{\mathrm{D}}, \mathrm{D}_{2}\right)$ \\
\hline$-0.5 \alpha$ to $\left(A_{D}, D_{1}\right)$ & $-0.5 \alpha$ to $\left(\mathrm{B}_{\mathrm{D}}, \mathrm{D}_{1}\right)$ & $-\alpha$ to $\left(\mathrm{C}_{\mathrm{D}}, \mathrm{B}_{\mathrm{D}}\right)$ & $-0.66 \alpha$ to $\left(\mathrm{D}_{\mathrm{D}}, \mathrm{B}_{\mathrm{D}}\right)$ \\
\hline$-0.5 \alpha$ to $\left(\mathrm{D}_{2}, \mathrm{~A}_{\mathrm{D}}\right)$ & $-0.5 \alpha$ to $\left(\mathrm{D}_{1}, \mathrm{~B}_{\mathrm{D}}\right)$ & $-\alpha$ to $\left(A_{D}, C_{D}\right)$ & $-0.66 \alpha$ to $\left(\mathrm{D}_{2}, \mathrm{D}_{\mathrm{D}}\right)$ \\
\hline$-0.5 \alpha$ to $\left(\mathrm{D}_{1}, \mathrm{~A}_{\mathrm{D}}\right)$ & $-0.5 \alpha$ to $\left(\mathrm{D}_{1}, \mathrm{~B}_{\mathrm{D}}\right)$ & $-\alpha$ to $\left(B_{D}, C_{D}\right)$ & $-0.66 \alpha$ to $\left(\mathrm{B}_{\mathrm{D}}, \mathrm{D}_{\mathrm{D}}\right)$ \\
\hline$-0.5 \lambda$ to $\left(A_{M}, D_{2}\right)$ & $-0.5 \lambda$ to $\left(\mathrm{B}_{\mathrm{M}}, \mathrm{D}_{1}\right)$ & $-\lambda$ to $\left(C_{M}, A_{D}\right)$ & $-0.66 \lambda$ to $\left(D_{M}, D_{2}\right)$ \\
\hline$-0.5 \lambda$ to $\left(A_{M}, D_{1}\right)$ & $-0.5 \lambda$ to $\left(D_{M}, D_{1}\right)$ & $-\lambda$ to $\left(\mathrm{C}_{\mathrm{M}}, \mathrm{B}_{\mathrm{D}}\right)$ & $-0.66 \lambda$ to $\left(\mathrm{D}_{\mathrm{M}}, \mathrm{B}_{\mathrm{D}}\right)$ \\
\hline$-0.5 \lambda$ to $\left(\mathrm{D}_{2}, \mathrm{~A}_{\mathrm{M}}\right)$ & $-0.5 \lambda$ to $\left(\mathrm{D}_{1}, \mathrm{D}_{\mathrm{M}}\right)$ & $-\lambda$ to $\left(A_{D}, C_{M}\right)$ & $-0.66 \lambda$ to $\left(\mathrm{D}_{2}, \mathrm{D}_{\mathrm{M}}\right)$ \\
\hline$-0.5 \lambda$ to $\left(\mathrm{D}_{1}, \mathrm{~A}_{\mathrm{M}}\right)$ & $-0.5 \lambda$ to $\left(D_{1}, B_{M}\right)$ & $-\lambda$ to $\left(\mathrm{B}_{\mathrm{D}}, \mathrm{C}_{\mathrm{M}}\right)$ & $-0.66 \lambda$ to $\left(\mathrm{B}_{\mathrm{D}}, \mathrm{D}_{\mathrm{M}}\right)$ \\
\hline$-0.5 \lambda$ to $\left(A_{D}, M_{1}\right)$ & $-0.5 \lambda$ to $\left(\mathrm{B}_{\mathrm{D}}, \mathrm{M}_{1}\right)$ & $-\lambda$ to $\left(C_{D}, A_{M}\right)$ & $-0.66 \lambda$ to $\left(\mathrm{D}_{\mathrm{D}}, \mathrm{M}_{2}\right)$ \\
\hline$-0.5 \lambda$ to $\left(\mathrm{A}_{\mathrm{D}}, \mathrm{M}_{1}\right)$ & $-0.5 \lambda$ to $\left(\mathrm{B}_{\mathrm{D}}, \mathrm{M}_{2}\right)$ & $-\lambda$ to $\left(\mathrm{C}_{\mathrm{D}}, \mathrm{B}_{\mathrm{M}}\right)$ & $-0.66 \lambda$ to $\left(\mathrm{D}_{\mathrm{D}}, \mathrm{B}_{\mathrm{M}}\right)$ \\
\hline$-0.5 \lambda$ to $\left(\mathrm{M}_{1}, \mathrm{~A}_{\mathrm{D}}\right)$ & $-0.5 \lambda$ to $\left(\mathrm{M}_{1}, \mathrm{~B}_{\mathrm{D}}\right)$ & $-\lambda$ to $\left(A_{M}, C_{D}\right)$ & $\lambda$ to $\left(M_{2}, D_{D}\right)$ \\
\hline$-0.5 \lambda$ to $\left(M_{1}, A_{D}\right)$ & $-0.5 \lambda$ to $\left(\mathrm{M}_{2}, \mathrm{~B}_{2}\right)$ & $-\lambda$ to $\left(B_{M}, C_{D}\right)$ & $\lambda$ to $\left(\mathrm{B}_{\mathrm{M}}, \mathrm{D}_{\mathrm{D}}\right)$ \\
\hline$-0.5 \beta$ to $\left(A_{M}, M_{1}\right)$ & $-0.5 \beta$ to $\left(\mathrm{B}_{\mathrm{M}}, \mathrm{M}_{1}\right)$ & $-\beta$ to $\left(\mathrm{C}_{\mathrm{M}}, \mathrm{A}_{\mathrm{M}}\right)$ & $-0.66 \beta$ to $\left(\mathrm{D}_{\mathrm{M}}, \mathrm{M}_{2}\right)$ \\
\hline$-0.5 \beta$ to $\left(\mathrm{A}_{\mathrm{M}}, \mathrm{M}_{1}\right)$ & $-0.5 \beta$ to $\left(\mathrm{B}_{\mathrm{M}}, \mathrm{M}_{2}\right)$ & $-\beta$ to $\left(\mathrm{C}_{\mathrm{M}}, \mathrm{B}_{\mathrm{M}}\right)$ & $-0.66 \beta$ to $\left(\mathrm{D}_{\mathrm{M}}, \mathrm{B}_{\mathrm{M}}\right)$ \\
\hline$-0.5 \beta$ to $\left(\mathrm{M}_{1}, \mathrm{~A}_{\mathrm{M}}\right)$ & $-0.5 \beta$ to $\left(\mathrm{M}_{1}, \mathrm{~B}_{\mathrm{M}}\right)$ & $-\beta$ to $\left(A_{M}, C_{M}\right)$ & $-0.66 \beta$ to $\left(\mathrm{M}_{2}, \mathrm{D}_{\mathrm{M}}\right)$ \\
\hline$-0.5 \beta$ to $\left(\mathrm{M}_{1}, \mathrm{~A}_{\mathrm{M}}\right)$ & $-0.5 \beta$ to $\left(\mathrm{M}_{2}, \mathrm{~B}_{\mathrm{M}}\right)$ & $-\beta$ to $\left(\mathrm{B}_{\mathrm{M}}, \mathrm{C}_{\mathrm{M}}\right)$ & $\left(B_{M}, D_{M}\right)$ \\
\hline $0.25 \alpha$ to $\left(\mathrm{D}_{2}, \mathrm{D}_{2}\right)$ & $0.25 \alpha$ to $\left(\mathrm{D}_{1}, \mathrm{D}_{1}\right)$ & $0.5 \alpha$ to $\left(\mathrm{A}_{\mathrm{D}}, \mathrm{A}_{\mathrm{D}}\right)$ & $\left.\mathrm{D}_{2}, \mathrm{D}_{2}\right)$ \\
\hline$\alpha$ to $\left(D_{2}, D_{1}\right)$ & $0.25 \alpha$ to $\left(\mathrm{D}_{1}, \mathrm{D}_{1}\right)$ & to $\left(A_{D}, B_{D}\right)$ & $0.33 \alpha$ to $\left(\mathrm{D}_{2}, \mathrm{~B}_{\mathrm{D}}\right)$ \\
\hline $0.25 \alpha$ to $\left(\mathrm{D}_{1}, \mathrm{D}_{2}\right)$ & $0.25 \alpha$ to $\left(\mathrm{D}_{1}, \mathrm{D}_{1}\right)$ & $0.5 \alpha$ to $\left(B_{D}, A_{D}\right)$ & $3 \alpha$ to $\left(\mathrm{B}_{\mathrm{D}}, \mathrm{D}_{2}\right)$ \\
\hline $0.25 \alpha$ to $\left(\mathrm{D}_{1}, \mathrm{D}_{1}\right)$ & $0.25 \alpha$ to $\left(\mathrm{D}_{1}, \mathrm{D}_{1}\right)$ & $0.5 \alpha$ to $\left(\mathrm{B}_{\mathrm{D}}, \mathrm{B}_{\mathrm{D}}\right)$ & $0.33 \alpha$ to $\left(\mathrm{B}_{\mathrm{D}}, \mathrm{B}_{\mathrm{D}}\right)$ \\
\hline $0.25 \lambda$ to $\left(\mathrm{D}_{2}, \mathrm{M}_{1}\right)$ & $0.25 \lambda$ to $\left(\mathrm{D}_{1}, \mathrm{M}_{1}\right)$ & $0.5 \lambda$ to $\left(\mathrm{A}_{\mathrm{D}}, \mathrm{A}_{\mathrm{M}}\right)$ & $\lambda$ to $\left(\mathrm{D}_{2}, \mathrm{M}_{2}\right)$ \\
\hline $0.25 \lambda$ to $\left(\mathrm{D}_{2}, \mathrm{M}_{1}\right)$ & $0.25 \lambda$ to $\left(\mathrm{D}_{1}, \mathrm{M}_{2}\right)$ & $.5 \lambda$ to $\left(A_{D}, B_{M}\right)$ & $3 \lambda$ to $\left(D_{2}, B_{M}\right)$ \\
\hline $0.25 \lambda$ to $\left(\mathrm{D}_{1}, \mathrm{M}_{1}\right)$ & $0.25 \lambda$ to $\left(\mathrm{D}_{1}, \mathrm{M}_{1}\right)$ & $0.5 \lambda$ to $\left(\mathrm{B}_{\mathrm{D}}, \mathrm{A}_{\mathrm{M}}\right)$ & $0.33 \lambda$ to $\left(\mathrm{B}_{\mathrm{D}}, \mathrm{M}_{2}\right)$ \\
\hline $\begin{array}{l}0.25 \lambda \text { to }\left(\mathrm{D}_{1}, \mathrm{M}_{1}\right) \\
0.25 \lambda \text { to }\left(\mathrm{M}_{1}, \mathrm{D}_{2}\right)\end{array}$ & $\begin{array}{l}0.25 \lambda \text { to }\left(\mathrm{D}_{1}, \mathrm{M}_{2}\right) \\
0.25 \lambda \text { to }\left(\mathrm{M}_{1}, \mathrm{D}_{1}\right)\end{array}$ & $\begin{array}{l}0.5 \lambda \text { to }\left(\mathrm{B}_{\mathrm{D}}, \mathrm{B}_{\mathrm{M}}\right) \\
0.5 \lambda \text { to }\left(\mathrm{A}_{\mathrm{M}}, \mathrm{A}_{\mathrm{D}}\right)\end{array}$ & $\begin{array}{l}0.33 \lambda \text { to }\left(\mathrm{B}_{\mathrm{D}}, \mathrm{B}_{\mathrm{M}}\right) \\
0.33 \lambda \text { to }\left(\mathrm{M}_{2}, \mathrm{D}_{2}\right)\end{array}$ \\
\hline $0.25 \lambda$ to $\left(\mathrm{M}_{1}, \mathrm{D}_{2}\right)$ & $0.25 \lambda$ to $\left(\mathrm{M}_{2}, \mathrm{D}_{1}\right)$ & $0.5 \lambda$ to $\left(\mathrm{B}_{\mathrm{M}}, \mathrm{A}_{\mathrm{D}}\right)$ & $0.33 \lambda$ to $\left(\mathrm{B}_{\mathrm{M}}, \mathrm{D}_{2}\right)$ \\
\hline $0.25 \lambda$ to $\left(\mathrm{M}_{1}, \mathrm{D}_{1}\right)$ & $0.25 \lambda$ to $\left(\mathrm{M}_{1}, \mathrm{D}_{1}\right)$ & $0.5 \lambda$ to $\left(\mathrm{A}_{\mathrm{M}}, \mathrm{B}_{\mathrm{D}}\right)$ & $0.33 \lambda$ to $\left(\mathrm{M}_{2}, \mathrm{~B}_{\mathrm{D}}\right)$ \\
\hline $0.25 \lambda$ to $\left(\mathrm{M}_{1}, \mathrm{D}_{1}\right)$ & $0.25 \lambda$ to $\left(\mathrm{M}_{2}, \mathrm{D}_{1}\right)$ & $0.5 \lambda$ to $\left(\mathrm{B}_{\mathrm{M}}, \mathrm{B}_{\mathrm{D}}\right)$ & $0.33 \lambda$ to $\left(\mathrm{B}_{\mathrm{M}}, \mathrm{B}_{\mathrm{D}}\right)$ \\
\hline $0.25 \beta$ to $\left(\mathrm{M}_{1}, \mathrm{M}_{1}\right)$ & $0.25 \beta$ to $\left(\mathrm{M}_{1}, \mathrm{M}_{1}\right)$ & $0.5 \beta$ to $\left(\mathrm{A}_{\mathrm{M}}, \mathrm{A}_{\mathrm{M}}\right)$ & $0.33 \beta$ to $\left(\mathrm{M}_{2}, \mathrm{M}_{2}\right)$ \\
\hline $0.25 \beta$ to $\left(\mathrm{M}_{1}, \mathrm{M}_{1}\right)$ & $0.25 \beta$ to $\left(\mathrm{M}_{1}, \mathrm{M}_{2}\right)$ & $0.5 \beta$ to $\left(\mathrm{A}_{\mathrm{M}}, \mathrm{B}_{\mathrm{M}}\right)$ & $0.33 \beta$ to $\left(\mathrm{M}_{2}, \mathrm{~B}_{\mathrm{M}}\right)$ \\
\hline $0.25 \beta$ to $\left(\mathrm{M}_{1}, \mathrm{M}_{1}\right)$ & $0.25 \beta$ to $\left(\mathrm{M}_{2}, \mathrm{M}_{1}\right)$ & $0.5 \beta$ to $\left(\mathrm{B}_{\mathrm{M}}, \mathrm{A}_{\mathrm{M}}\right)$ & $0.33 \beta$ to $\left(\mathrm{B}_{\mathrm{M}}, \mathrm{M}_{2}\right)$ \\
\hline $0.25 \beta$ to $\left(\mathrm{M}_{1}, \mathrm{M}_{1}\right)$ & $0.25 \beta$ to $\left(\mathrm{M}_{2}, \mathrm{M}_{2}\right)$ & $0.5 \beta$ to $\left(\mathrm{B}_{\mathrm{M}}, \mathrm{B}_{\mathrm{M}}\right)$ & $0.33 \beta$ to $\left(\mathrm{B}_{\mathrm{M}}, \mathrm{B}_{\mathrm{M}}\right)$ \\
\hline
\end{tabular}


The algorithm can be extended to multiple traits, as pointed out by a referee, as follows. Let:

$i_{l}=$ equation number of individual $i$ for the $l$ th trait;

$j_{l}=$ equation number of the sire of $i$ or its sire's group (if base sire) for trait $l$;

$k_{l}=$ equation number of the dam of $i$ or its dam's group (if base dam) for trait $l$. Let $s=0,1,2$, be the number of base parents of $i$. For each animal calculate $x=4 /(s+2)$. Finally, letting $t$ be the number of traits, for $m=1$ to $t$ and $n=1$ to $t$, add to $\mathbf{A}^{*}$ the following 9 contributions:

$\begin{aligned} \text { Contribution } & \text { To element (s) } \\ g^{m n} x & \left(i_{m}, i_{n}\right) \\ -0.5 g^{m n} x & \left(i_{m}, j_{n}\right) ;\left(j_{m}, i_{n}\right) ;\left(i_{m}, k_{n}\right) ;\left(k_{m}, i_{n}\right) \\ 0.25 g^{m n} x & \left(j_{m}, j_{n}\right) ;\left(j_{m}, k_{n}\right) ;\left(k_{m}, j_{n}\right) ;\left(k_{m}, k_{n}\right)\end{aligned}$

where $g^{m n}$ is element $(m, n)$ of the inverse of the $t \times t$ matrix of additive variances and covariance among the $t$ traits. Note that for $t=2$ there are 4 passes through the loops of $m$ and $n$, resulting in $9 \times 4=36$ contributions, as in the case of direct and maternal effects.

\section{DISCUSSION}

The procedure presented here allows for different criteria to be used when assigning genetic groups for direct and for maternal effects. If groups for direct and maternal effects are assigned using the same criterion, our formulation gives the same results as those of Van Vleck (1990). The method can be implemented by a simple modification of existing algorithms for direct effects only. The modification requires different addressing for genetic groups. This can be accomplished by writing extra columns on a file containing pedigree information indicating the group assignment for maternal effects of the "phantom" parents.

Assigning different groups may be used to account for different genetic trends on a maternally influenced trait. For example, Benyshek et al (1988) analyzed weaning weight records of beef calves and found a positive genetic trend for direct effects, whereas the trend for maternal effects was practically null. In this case, unknown animals may be assigned to just one group (or none) for maternal effects while being assigned to several groups for direct effects. Differential genetic grouping can also be employed when genetic trends display genetic (piecewise) patterns throughout the years. For other situations, assigning different groups to direct and maternal effects may not be feasible.

Quaas (1988) warned about using complex strategies to assign groups to missing individuals so that confounding between genetic groups and other effects in the model is avoided. If groups for direct and maternal effects are to be fitted there is also the possibility of confounding between genetic groups for both types of effects. Consider the matrix $\left[\mathbf{Z}_{o} \mathbf{Q}_{o} \mid \mathbf{Z}_{m} \mathbf{Q}_{m}\right]$ that relates records to genetic groups. By definition, $\mathbf{Z}_{o}$ (which relates records to direct $\mathrm{BV}$ ), is always different from 
$\mathbf{Z}_{m}$ (which relates records to maternal BV). However, if $\mathbf{Q}_{o}=\mathbf{Q}_{m}$, ie the same criterion is used to assign genetic groups for direct and maternal effects, the risk of confounding both types of effects or with other effects in the model is higher than the case of $\mathbf{Q}_{o}$ different from $\mathbf{Q}_{m}$.

A referee pointed out an example indicating that lack of estimatibility may not always be produced by confounding but also due to lack of expression of the maternal effects. The problem arises when there are animals with records and. unknown sires and males and females are grouped separately. Whereas the direct effect for the "phantom" sire group would be estimable the maternal effect would not, because none of these sires has female descendents with recorded progeny. As direct effects are expressed long before maternal effects, direct group effects will be estimable well in advance of maternal group effects, the referee indicated. He goes further to suggest that, in this case, one can resort to form groups with both males and females or have the last maternal group correspond to a much longer time period.

In the present work breeding values for direct and maternal effects of missing or "phantom" dams of individuals with records are suggested to be included in the vector of solutions to correctly specify the variance-covariance matrix of the observations, as in Van Vleck (1990). As a consequence the number of equations to be solved increases. However, the procedure of differential grouping is independent of enlarging the vector of breeding values to include those of the "phantom" dams. If other methods of specifying the variance of the records are found, the procedure presented here may still be applicable.

\section{ACKNOWLEDGMENTS}

The referees provided many comments that greatly improved the original version of this paper. Any remaining mistake is the responsibility of the first author. RJC Cantet wishes to thank the University of Illinois and Universidad de Buenos Aires for financial support throughout his graduate studies.

\section{REFERENCES}

Bulmer MG (1985) The Mathematical Theory of Quantitative Genetics. Clarendon Press, Oxford

Benyshek LL, Johnson MH, Little DE, Bertrand JK, Kriese La (1988) Applications of an animal model in the United States beef cattle industry. J Dairy Sci 71 (suppl 2), 35-53

Henderson CR (1984) Applications of Linear Models in Animal Breeding. University of Guelph, Guelph, Ont, Canada

Henderson CR (1988) Theoretical basis and computational methods for a number of different animal models. J Dairy Sci 71 (suppl 2), 1-16

Quaas RL (1988) Additive genetic model with groups and relationships. J Dairy Sci 71, 1338-1345

Quaas RL, Pollak EJ (1980) Mixed model methodology for farm and ranch beef cattle testing programs. J Anim Sci 51, 1277-1287 
Quaas RL, Pollak EJ (1981) Modified equations for sire models with groups. J Dairy Sci 64, 1868-1872

Robinson GK (1986) Group effects and computing strategies for models for estimating breeding values. J Dairy Sci $69,3106-3111$

Van Vleck LD (1990) Breeding value prediction with maternal genetic groups. $J$ Anim Sci 68, 3998-4013

Westell RA, Quaas RL, Van Vleck LD (1988) Genetic groups in animal model. J Dairy Sci 71, 1310-1318

Willham RL (1963) The covariance between relatives for characters composed of components contributed by related individuals. Biometrics 19, 18-27 